\title{
FORMULATION AND EVALUATION OF PULSATILE DRUG DELIVERY SYSTEM OF SALBUTAMOL SULFATE FOR THE CHRONOTHERAPY OF ASTHMA
}

\author{
CHIRANJIBI ADHIKARI, GURURAJ S KULKARNI*, SHIVAKUMAR SWAMY
}

\author{
Department of Pharmaceutics, Mallige College of Pharmacy, Bengaluru, Karnataka, India. Email: skguru2006@gmail.com
}

Received: 01 June 2017, Revised and Accepted: 29 May 2018

\begin{abstract}
Objective: The main objective of the present study was to design and evaluate a time-controlled single unit oral pulsatile drug delivery system containing salbutamol sulfate for the prevention of nocturnal asthma attacks.

Methods: Drug containing core tablets (C1-C10) with different composition of superdisintegrants such as sodium starch glycolate, croscarmellose sodium, and crospovidone were prepared by direct compression technique. The fast disintegrating core tablet formulation was selected, and press-coated tablets (P1-P11) were prepared with different compositions of hydrophobic and hydrophilic polymers: Ethylcellulose-20 (EC-20), hydroxypropyl methylcellulose K4M, and low substituted hydroxypropyl cellulose (L-HPC LH11). The coating polymers were selected and quantified based on in vitro lag time and drug release profile in simulated gastric and intestinal fluids.
\end{abstract}

Results: Formulation C10 with 7.5\% crospovidone showed least disintegrating time, i.e., 0.31 min and was selected as the best immediate release core tablet. The press-coated tablet formulation P11 having $360 \mathrm{mg}$ barrier layer of EC-20 and L-HPC LH11 in ratio 14:1 over the core tablet C10 showed rapid and complete drug release nearly after $6 \mathrm{~h}$ lag time. Accelerated stability studies of the optimized formulation P11 indicated no significant difference in release profile after a period of 6 months.

Conclusion: The in vitro dissolution study showed that lag time before drug release was highly affected by the coating level and nature of coating polymer used. Time-controlled pulsatile release tablets can be prepared using press-coating techniques.

Keywords: Salbutamol sulfate, Nocturnal asthma, Time-controlled pulsatile tablet, Press-coated tablet, $6 \mathrm{~h}$ lag time, Burst release.

(C) 2018 The Authors. Published by Innovare Academic Sciences Pvt Ltd. This is an open access article under the CC BY license (http://creativecommons. org/licenses/by/4. 0/) DOI: http://dx.doi.org/10.22159/ajpcr.2018.v11i9.20423

\section{INTRODUCTION}

Chronopharmaceutics is an approach to deliver drugs at a time that match biological requisite for a specified disease treatment or prevention [1,2]. Pulsatile drug delivery systems (PDDS) are the chronopharmaceutical approach intended to release the drug on specific pre-programmed patterns and are characterized by a lag time [3].

Asthma is a chronic inflammatory disease of the respiratory tract, the most common chronic disease among children [4]. Nocturnal asthma follows circadian rhythms where increasing to airway resistance and worsening of lung function are observed during the early morning time. Two-thirds of asthmatics suffer from nocturnal asthma symptoms. The risk of asthma attacks is 100 -fold greater during nighttime sleep than during daytime activity. Forced expiratory volume in $1 \mathrm{sec}$ is found to be lower at 4 am $[5,6]$. Histamine concentrations peak at a level that coincided with the greatest degree of bronchoconstriction at 4 am [1]. Nocturnal bronchoconstriction is driven by circadian changes in epinephrine, cortisol, histamine, AMP, melatonin, vagal tone, body temperature, lower airway secretions, etc. $[7,8]$.

Salbutamol is short-acting, highly selective Beta 2-adrenoceptor agonist; cardiac side effects are less prominent. It is used to treat asthma by relaxing the bronchial smooth muscle to produce immediate dilatation of the bronchi $[9,10]$. Oral Salbutamol sulfate tablet $(2-4 \mathrm{mg})$ is readily absorbed from the gastrointestinal (GI) tract, and the absolute bioavailability is $44 \%$ with peak plasma concentration at $1-3 \mathrm{~h}$ [11]. However, salbutamol sulfate has short biological half-life (3.8-6 h) and high first-pass metabolism. High doses or prolonged use may cause hypokalemia . Time-controlled pulsatile release dosage forms of salbutamol sulfate can curtail these disadvantages [12].
Treating asthma with immediate release dosage forms may be impractical if the symptoms of asthma are pronounced during the night or early morning. Pulsatile-release dosage forms may be taken at bedtime with a programmed start of drug release in early morning hours when the risk of asthmatic attacks is the greatest [13].

We have selected a single pulse system because of the advantage of ease of manufacturing. Reason to select compress-coated technique is that it overcomes instability of salbutamol sulfate (hygroscopic drug) as compared to the regular pan-coated techniques $[14,15]$.

\section{METHODS}

Salbutamol sulfate was obtained as a gift sample from Amtech Med Pvt. Ltd., Nepal. Ethyl cellulose-20 (EC-20), hydroxypropyl methylcellulose K4M (HPMC K4M), low substituted hydroxypropyl cellulose LH11 (L-HPC LH11), sodium starch glycolate (SSG), croscarmellose sodium (CCS), crospovidone, polyvinylpyrrolidone K-30, microcrystalline cellulose PH 102, magnesium stearate, aerosil 200, and lactose monohydrate used were of pharmacopoeial grade.

A novel technique "time-controlled PDDS" was designed with drug contained in fast disintegrating core and press-coated with suitable barrier layer. Drug-containing core tablets (C1-C10) with different composition of superdisintegrates such as SSG, CCS, and crospovidone were prepared by direct compression technique. The fast disintegrating core tablet formulation was selected, and presscoated tablets (P1-P11) were prepared with different compositions of hydrophobic and hydrophilic polymers: EC-20, HPMC K4M, and L-HPC LH11. The coating polymers were selected and quantified based on in vitro lag time and drug release profile in simulated gastric and intestinal fluids. 
Compatibility analysis

The polymers used in different formulations were mixed with the drug separately in equal ratios, and the samples of the final formula of the press-coated tablet were analyzed through Fourier-transform infrared (FTIR) spectroscopy. FTIR spectra $\left(400-4400 \mathrm{~cm}^{-1}\right)$ were obtained on a Jasco FTIR 460 Plus spectrophotometer. KBR pellets were prepared gently by mixing the $1 \mathrm{mg}$ sample with $100 \mathrm{mg}$ potassium bromide. The characteristic peaks were recorded.

Preparation of mixed blend of drug and excipients of the immediate release core tablet

All the ingredients were passed through mesh No. 60. The required amount of each ingredient was taken from specified a formulation that is from C1 to C10 as shown in Table 1, and all the ingredients were dry blended. The powder blend was evaluated for flow properties such as angle of repose, bulk density, tapped density, compressibility index, and Hausner's ratio.

\section{Formulation of core tablets by direct compression}

The ingredients as depicted in Table 1 except magnesium stearate and aerosil-200 were dry blended for $15 \mathrm{~min}$ followed by addition of quitted ingredients and dry blending for another $5 \mathrm{~min}$. The mixed blend of drug and excipients was compressed using a single punch rotary punching machine to produce round tablets weighing $120 \mathrm{mg}$ with a diameter of $8 \mathrm{~mm}$.

\section{Evaluation of core tablets}

All the prepared tablets were evaluated for average weight, hardness, friability, assay, drug content uniformity, in vitro disintegration time, and in vitro dissolution.

\section{Dissolution rate studies of core tablets}

Dissolution rate studies of salbutamol sulfate from all core tablet formulations were performed using Lab, India DS 8000, an eight-stage dissolution rate testing apparatus with paddle. The dissolution fluid was $500 \mathrm{ml}$ of phosphate buffer $\mathrm{pH}$ 6.8. The test was performed at 50 $\mathrm{rpm}$ and at a temperature of $37 \pm 0.5^{\circ} \mathrm{C}$. Samples of dissolution medium were withdrawn through a filter of $0.45 \mu \mathrm{m}$ at different time intervals and assayed for salbutamol sulfate by measuring absorbance at $276 \mathrm{~nm}$. The dissolution experiments were conducted for six tablets from each formulation.
Formulation of mixed blend for barrier layer

All the ingredients were passed through mesh No. 60. The required amount of every ingredient was taken from specified formulations of the barrier layer that is from P1 to P10 as depicted in Table 2, and all the ingredients were dry blended.

\section{Preparation of press-coated tablets}

The core tablets were press-coated with prepared barrier blends as per the mentioned formulas from P1 to P10. Initially, half of barrier layer material was weighed and transferred into a $12.6 \mathrm{~mm}$ die, and then the core tablet was placed manually at the center. The remaining half of the barrier layer material was added into the die and compressed.

\section{Evaluation of press-coated tablets}

The prepared tablets were evaluated for average weight, hardness, and in vitro dissolution.

\section{Dissolution rate studies of press-coated tablets}

Dissolution rate studies were performed for all the press coated tablets using Labindia DS 8000, an eight-stage dissolution rate testing apparatus with paddle. The dissolution fluid was $500 \mathrm{ml} 0.1 \mathrm{M} \mathrm{HCl}$ for $2 \mathrm{~h}$, which was replaced with phosphate buffer $\mathrm{pH} 6.8$. The test was performed at $50 \mathrm{rpm}$ and at a temperature of $37 \pm 0.5^{\circ} \mathrm{C}$. Samples were withdrawn for every $1 / 2 \mathrm{~h}$ up to $9 \mathrm{~h}$ and the lag times were observed for every batch tablet, and the collected samples were analyzed for the drug released by ultraviolet spectrophotometer at $276 \mathrm{~nm}$ to know whether the formulations show sigmoidal release.

\section{RESULTS}

\section{Compatibility analysis}

The characteristic peaks from IR spectra of the drug are shown in Fig. 1, and a physical mixture of the drug and polymers used is shown in Figs. 2-5.

\section{Evaluation of blends and tablets of immediate release cores}

The flow and compressibility properties of the blends of all the formulations of the core tablet are given in Table 4. The tablet characteristics of the prepared core tablets are shown in Table 5. The results of the dissolution profiles of all the formulations are represented graphically in Fig. 6.

Table 1: Manufacturing formula of the core tablet

\begin{tabular}{|c|c|c|c|c|c|c|c|c|c|c|}
\hline \multirow[t]{2}{*}{ Name of the ingredients } & \multicolumn{10}{|c|}{ Quantity (mg/tablet) } \\
\hline & C1 & $\mathrm{C} 2$ & C3 & $\mathrm{C4}$ & C5 & C6 & C7 & C8 & C9 & C10 \\
\hline Salbutamol sulfate & 4.8 & 4.8 & 4.8 & 4.8 & 4.8 & 4.8 & 4.8 & 4.8 & 4.8 & 4.8 \\
\hline SSG & - & 3 & 6 & 9 & - & - & - & - & - & - \\
\hline CCS & - & - & - & - & 3 & 6 & 9 & - & - & - \\
\hline Crospovidone & - & - & - & - & - & - & - & 3 & 6 & 9 \\
\hline MCC PH 102 & 30 & 30 & 30 & 30 & 30 & 30 & 30 & 30 & 30 & 30 \\
\hline PVP K-30 & 6 & 6 & 6 & 6 & 6 & 6 & 6 & 6 & 6 & 6 \\
\hline Lactose monohydrate & 76 & 73 & 70 & 67 & 73 & 70 & 67 & 73 & 70 & 67 \\
\hline Magnesium stearate & 2 & 2 & 2 & 2 & 2 & 2 & 2 & 2 & 2 & 2 \\
\hline Aerosil-200 & 1.2 & 1.2 & 1.2 & 1.2 & 1.2 & 1.2 & 1.2 & 1.2 & 1.2 & 1.2 \\
\hline Total weight of core tablets (mg) & 120 & 120 & 120 & 120 & 120 & 120 & 120 & 120 & 120 & 120 \\
\hline
\end{tabular}

MCC PH 102: Microcrystalline cellulose PH 102, SSG: Sodium starch glycolate, CCS: Croscarmellose sodium, PVP K-30: Polyvinylpyrrolidone K-30

Table 2: Manufacturing formula of barrier layer for press-coated tablets

\begin{tabular}{|c|c|c|c|c|c|c|c|c|c|c|c|}
\hline \multirow[t]{2}{*}{ Name of ingredients } & \multicolumn{11}{|c|}{ Quantity (mg/tablet) } \\
\hline & P1 & P2 & P3 & P4 & P5 & P6 & P7 & P8 & P9 & P10 & P11 \\
\hline HPMC K4M & 240 & 300 & 360 & 345 & 330 & 315 & 300 & - & - & & \\
\hline EC-20 & - & - & - & 15 & 30 & 45 & 60 & 300 & 315 & 330 & 336 \\
\hline L-HPC LH11 & - & - & - & - & - & - & - & 60 & 45 & 30 & 24 \\
\hline Weight of coating material (mg) & 240 & 300 & 360 & 360 & 360 & 360 & 360 & 360 & 360 & 360 & 360 \\
\hline
\end{tabular}

HPMC K4M: Hydroxypropyl methylcellulose K4M, EC-20: Ethyl cellulose-20, L-HPC LH11: Low substituted hydroxypropyl cellulose LH11 


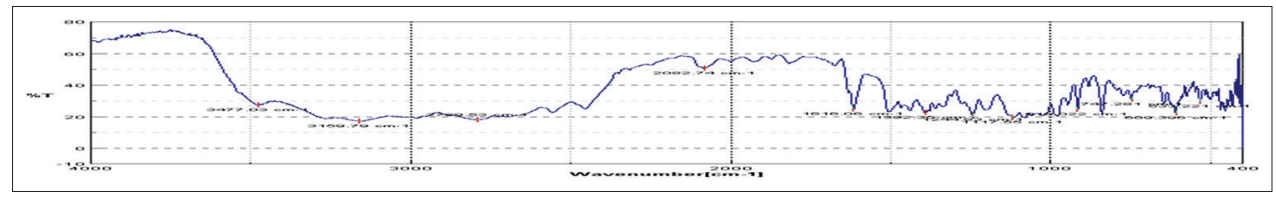

Fig. 1: Fourier-transform infrared spectra of salbutamol sulfate

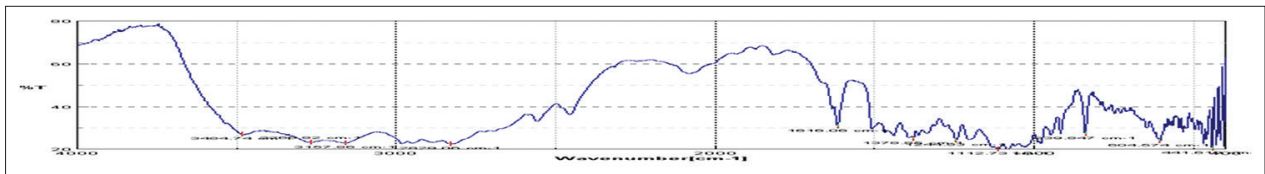

Fig. 2: Fourier-transform infrared spectra of pure salbutamol sulfate+hydroxypropyl methylcellulose K4M

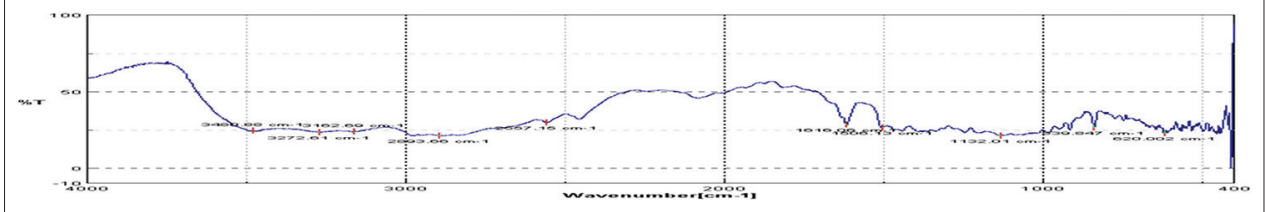

Fig. 3: Fourier-transform infrared spectra of pure salbutamol sulfate+hydroxypropyl methylcellulose K4M+EC 20

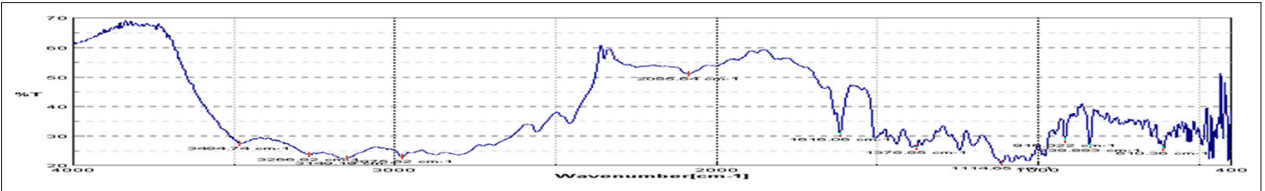

Fig. 4: Fourier-transform infrared spectra of pure salbutamol sulfate+L-hydroxypropyl cellulose LH11+EC 20

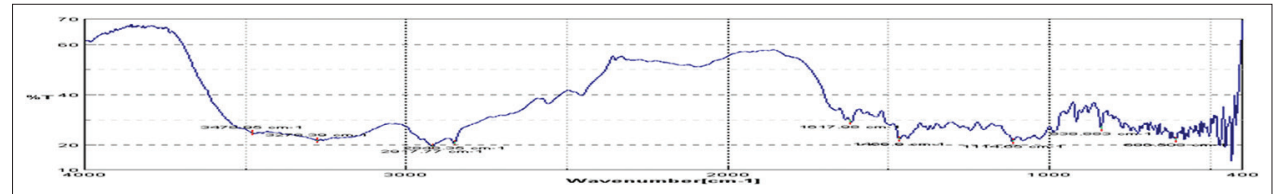

Fig. 5: Fourier-transform infrared spectra of final formulation

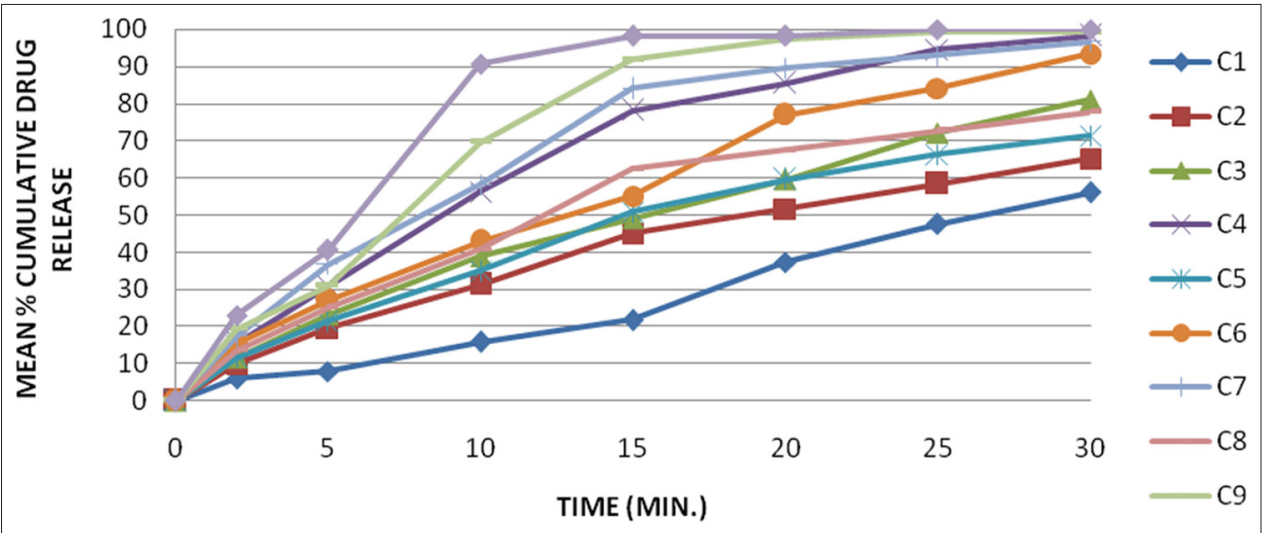

Fig. 6: Dissolution profiles of all the core tablet formulations

\section{Optimization of the core tablet formulation}

The core tablet $\mathrm{C} 10$ formulated with $7.5 \%$ crospovidone along with the other excipients shown less disintegration time $(0.31 \mathrm{~min})$. It accommodates a helping hand in obtaining burst release of the drug. C10 also showed better dissolution profile $\left(\mathrm{t}_{90}=10 \mathrm{~min}\right)$ and complied with all other parameters with less variation in results and hence was selected as the optimized core tablet formulation.
Drug release kinetics of the optimized core tablets

The correlation coefficient $\left(\mathrm{R}^{2}\right)$ values of the optimized formulation C10 as per different in vitro release kinetics model are shown in Table 6, and from the $\left(\mathrm{R}^{2}\right)$ values, it was found that the immediate release core tablets have followed the first-order kinetics. The first-order plot of the core tablet $\mathrm{C} 10$ is given in Figs. 7 and 8. 
Table 3: FTIR positions of characteristic bond vibrations of pure drug salbutamol sulfate and the drug with excipients

\begin{tabular}{lllllll}
\hline S. No & \multicolumn{2}{l}{$\begin{array}{l}\text { Various mode of bond vibrations } \\
\text { and wave number range }\left(\mathbf{c m}^{-1}\right)\end{array}$} & \multicolumn{5}{l}{ Observed FTIR positions of various bond vibrations in wave number $\left(\mathbf{c m}^{-1}\right)$} \\
\cline { 3 - 7 } & & Pure drug & Drug+HPMC & Drug+HPMC+EC & Drug+L-HPC+EC & Final formulation \\
\hline 1. & O-H stretching (3000-3700) & 3477.03 & 3484.74 & 3480.88 & 3484.76 & 3478.95 \\
2. & N-H bending (1500-1700) & 1616.06 & 1616.06 & 1616.06 & 1616.06 & 1617.98 \\
3. & O-H bending (1200-1500) & 1392.35 & 1378.85 & 1378.85 & 1378.85 & 1378.85 \\
4. & C-O stretching (900-1300) & 916.02 & 916.02 & 916.02 & 916.02 & 916.02 \\
\hline
\end{tabular}

FTIR: Fourier transform infrared, HPMC: Hydroxypropyl methylcellulose, L-HPC: Low substituted hydroxypropyl cellulose, EC: Ethylcellulose

Table 4: Evaluation of directly compressible blends of core tablet

\begin{tabular}{|c|c|c|c|c|c|}
\hline Formulation batch & $\begin{array}{l}\text { Bulk density } \\
\left(\mathrm{g} / \mathrm{cm}^{3}\right) \pm \operatorname{SD}(\mathrm{n}=3)\end{array}$ & $\begin{array}{l}\text { Tapped density } \\
\left(\mathrm{g} / \mathrm{cm}^{3}\right) \pm S D(\mathrm{n}=3)\end{array}$ & $\begin{array}{l}\text { Carr's index } \\
(\%) \pm S D(n=3)\end{array}$ & $\begin{array}{l}\text { Hausner's ratio } \\
\pm S D(n=3)\end{array}$ & $\begin{array}{l}\text { Angle of repose } \\
\left({ }^{\circ} \pm \operatorname{SD}(n=3)\right.\end{array}$ \\
\hline $\mathrm{C} 1$ & $0.57 \pm 0.01$ & $0.64 \pm 0.00$ & $12.93 \pm 1.09$ & $1.13 \pm 0.01$ & $24.7 \pm 0.35$ \\
\hline $\mathrm{C} 2$ & $0.58 \pm 0.00$ & $0.67 \pm 0.01$ & $13.0 \pm 0.87$ & $1.13 \pm 0.01$ & $24.19 \pm 0.35$ \\
\hline $\mathrm{C} 3$ & $0.59 \pm 0.01$ & $0.68 \pm 0.01$ & $12.8 \pm 0.87$ & $1.13 \pm 0.01$ & $23.84 \pm 0.37$ \\
\hline $\mathrm{C} 4$ & $0.60 \pm 0.01$ & $0.68 \pm 0.00$ & $12.8 \pm 0.87$ & $1.13 \pm 0.01$ & $23.78 \pm 0.31$ \\
\hline $\mathrm{C} 5$ & $0.57 \pm 0.01$ & $0.64 \pm 0.01$ & $12.2 \pm 0.17$ & $1.12 \pm 0.00$ & $24.45 \pm 0.27$ \\
\hline $\mathrm{C} 6$ & $0.57 \pm 0.00$ & $0.64 \pm 0.01$ & $12.9 \pm 0.98$ & $1.13 \pm 0.01$ & $24.81 \pm 0.08$ \\
\hline C8 & $0.53 \pm 0.01$ & $0.60 \pm 0.01$ & $13.1 \pm 0.17$ & $1.13 \pm 0.01$ & $24.59 \pm 0.41$ \\
\hline $\mathrm{C} 9$ & $0.51 \pm 0.00$ & $0.58 \pm 0.01$ & $12.48 \pm 0.73$ & $1.14 \pm 0.01$ & $24.42 \pm 0.33$ \\
\hline $\mathrm{C} 10$ & $0.49 \pm 0.01$ & $0.56 \pm 0.00$ & $12.43 \pm 0.13$ & $1.14 \pm 0.00$ & $24.38 \pm 0.35$ \\
\hline
\end{tabular}

SD: Standard deviation

Table 5: Evaluation of formulations of core tablet

\begin{tabular}{|c|c|c|c|c|c|c|}
\hline $\begin{array}{l}\text { Formulation } \\
\text { batch }\end{array}$ & $\begin{array}{l}\text { Weight variation } \\
\text { (mg) } \pm S D(n=20)\end{array}$ & $\begin{array}{l}\text { Hardness } \\
\left(\mathrm{kg} / \mathrm{cm}^{3}\right) \pm S D(n=3)\end{array}$ & $\begin{array}{l}\text { Thickness } \\
(\mathrm{mm}) \pm S D(n=3)\end{array}$ & $\begin{array}{l}\text { Friability } \\
(n=6)\end{array}$ & $\begin{array}{l}\text { Drug content } \\
(\%) \pm S D(n=3)\end{array}$ & $\begin{array}{l}\text { Disintegration time } \\
(\min ) \pm S D(n=3)\end{array}$ \\
\hline $\mathrm{C} 1$ & $121.1 \pm 1.43$ & $3.66 \pm 0.15$ & $1.98 \pm 0.03$ & 0.27 & $97.6 \pm 0.22$ & $14.71 \pm 0.30$ \\
\hline $\mathrm{C} 3$ & $121.2 \pm 1.33$ & $3.80 \pm 0.10$ & $1.97 \pm 0.03$ & 0.41 & $98.87 \pm 0.38$ & $3.35 \pm 0.37$ \\
\hline $\mathrm{C} 4$ & $120.5 \pm 1.24$ & $3.76 \pm 0.06$ & $2.00 \pm 0.06$ & 0.44 & $99.37 \pm 0.22$ & $1.73 \pm 0.26$ \\
\hline $\mathrm{C} 5$ & $121.1 \pm 1.73$ & $3.76 \pm 0.12$ & $1.99 \pm 0.04$ & 0.28 & $98.86 \pm 0.76$ & $2.68 \pm 0.14$ \\
\hline $\mathrm{C} 6$ & $120.3 \pm 1.39$ & $3.66 \pm 0.06$ & $1.95 \pm 0.05$ & 0.42 & $99.75 \pm 0.22$ & $2.19 \pm 0.09$ \\
\hline $\mathrm{C} 8$ & $120.4 \pm 1.48$ & $3.73 \pm 0.21$ & $1.97 \pm 0.05$ & 0.40 & $99.45 \pm 0.19$ & $1.12 \pm 0.10$ \\
\hline $\mathrm{C} 9$ & $120.7 \pm 1.13$ & $3.63 \pm 0.06$ & $2.01 \pm 0.06$ & 0.27 & $99.87 \pm 0.22$ & $0.48 \pm 0.04$ \\
\hline C10 & $120.6 \pm 1.09$ & $3.63 \pm 0.21$ & $1.98 \pm 0.04$ & 0.28 & $99.75 \pm 0.22$ & $0.31 \pm 0.02$ \\
\hline
\end{tabular}

SD: Standard deviation

Table 6: Correlation coefficient $\left(R^{2}\right)$ values of the optimized formulation $\mathrm{C10}$ as per different in vitro release kinetics plots

\begin{tabular}{ll}
\hline Kinetics model & $\mathbf{R}^{2}$ value \\
\hline Zero order & 0.744 \\
First order & 0.946 \\
Hixson-Crowell & 0.921 \\
Higuchi's & 0.897 \\
Korsmeyer-Peppas & 0.899 \\
\hline
\end{tabular}

Evaluation of press-coated tablets

The tablet characteristics of the prepared press coated tablets are shown in Table 7. The results of the dissolution profiles of all the formulations (P1-P11) are represented graphically in Figs. 9-13. Lag time and $\mathrm{t}_{90 \%}$ of all batch formulations (P1-P11) are shown in Table 8.

\section{Optimization of the barrier layer coating material}

Formulation P11, prepared by press-coating of the optimized core tablet C10 with the $360 \mathrm{mg}$ barrier layer of EC-20 and L-HPC LH11 in the ratio $14: 1$, provided pre-determined lag time $\left(\mathrm{t}_{10 \%}\right)$ that is nearly $6 \mathrm{~h}$. The coating material started rupturing at $5.9 \pm 0.02 \mathrm{~h}$ and showed the burst drug, release then after $\left(\mathrm{t}_{90 \%}=7 \mathrm{~h}\right)$. Hence, P11 was selected as the optimized pulsatile tablet formulation among all the 11 formulations.

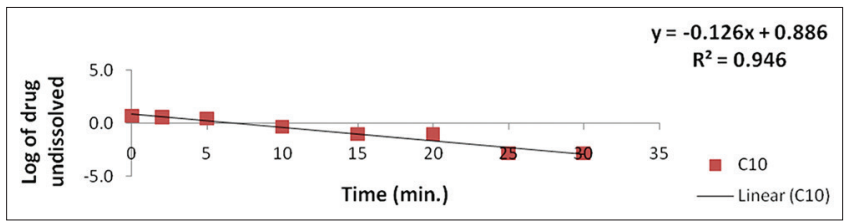

Fig. 7: In vitro release first-order plot of the core tablet formulation C10

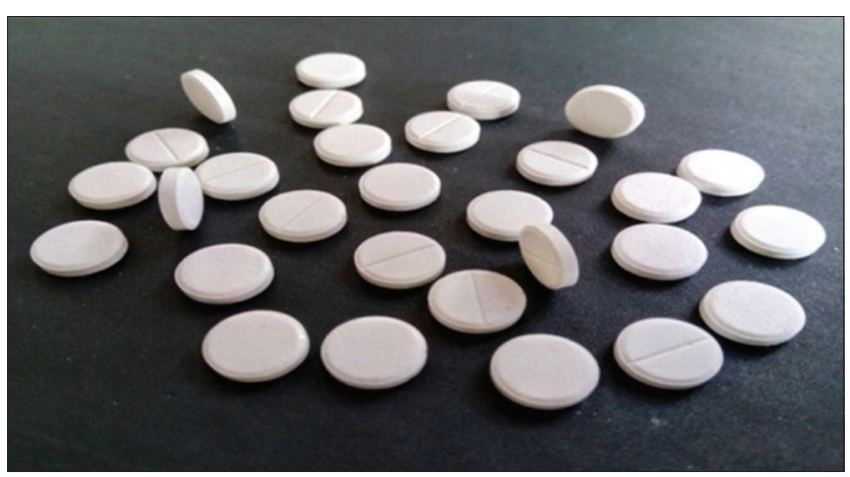

Fig. 8: Formulated core tablets each of $120 \mathrm{mg}$ 


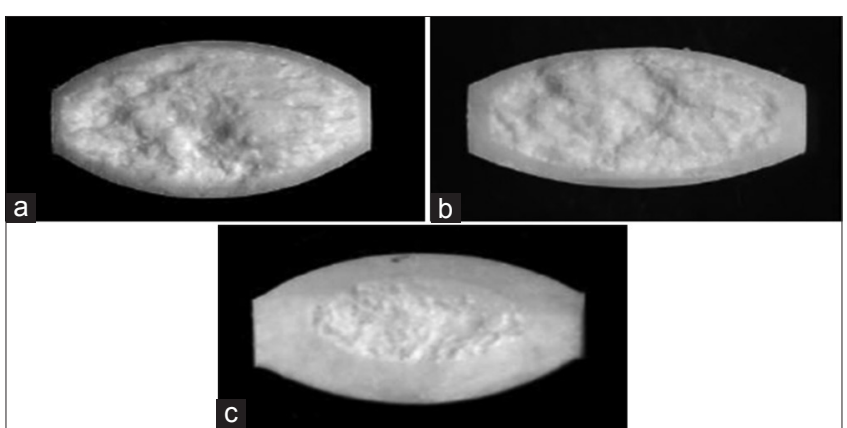

Fig. 9: Cross-sectional view of formulated press-coated tablets with varying in coating material weight. (a) $240 \mathrm{mg}$, (b) $300 \mathrm{mg}$, (c) $360 \mathrm{mg}$
Drug release kinetics of the optimized press-coated tablets

The $\mathrm{R}^{2}$ values of the optimized press-coated tablet (P11) as per different in vitro release kinetics model are shown in Table 9. The zero-order plot of the press-coated tablet P11 is given in Fig. 14.

\section{Stability studies}

6 months' stability study results for color, thickness, hardness, drug content, and dissolution profile are shown in Table 10.

\section{DISCUSSION}

Compatibility analysis

The characteristic peaks of the drug from IR spectra were also observed (Table 3 ) for the physical mixture of the drug and polymers used. No major changes in peaks of drug and drug with polymers indicates that compatibility between drug and polymers.

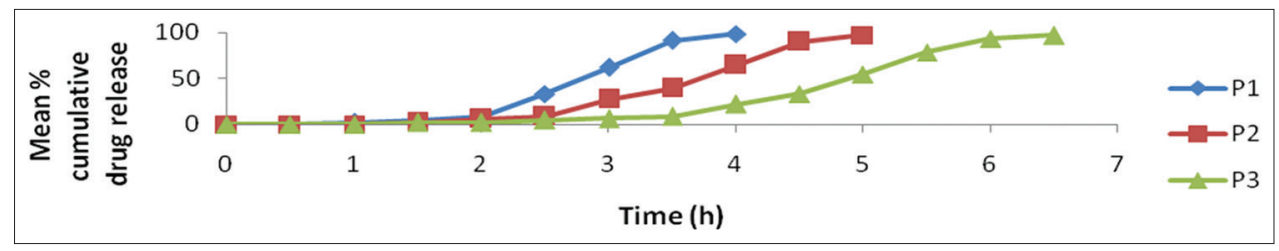

Fig. 10: Dissolution profile of compression-coated pulsatile tablets P1-P3

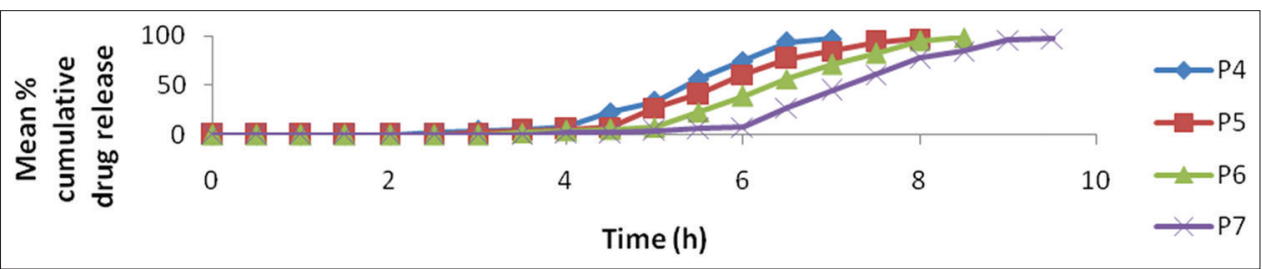

Fig. 11: Dissolution profile of compression-coated pulsatile tablets P4-P7

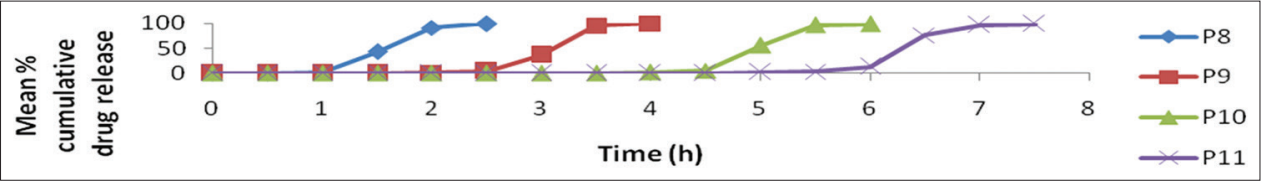

Fig. 12: Dissolution profile of compression-coated pulsatile tablets P8-P11

Table 7: Evaluation of press-coated tablets

\begin{tabular}{llll}
\hline Formulation batch & Weight variation $(\mathbf{m g}) \pm \mathbf{S D}(\mathbf{n}=\mathbf{2 0})$ & Hardness $\left.\mathbf{( k g} / \mathbf{c m}^{3}\right) \pm \mathbf{S D}(\mathbf{n}=\mathbf{3})$ & Thickness $(\mathbf{m m}) \pm \mathbf{S D}(\mathbf{n}=\mathbf{3})$ \\
\hline P1 & $361.4 \pm 4.63$ & $5.86 \pm 0.63$ & $3.93 \pm 0.03$ \\
P2 & $420.8 \pm 5.13$ & $7.73 \pm 0.42$ & $4.04 \pm 0.05$ \\
P3 & $480.7 \pm 4.33$ & $8.80 \pm 0.59$ & $4.88 \pm 0.03$ \\
P4 & $481.1 \pm 5.24$ & $8.46 \pm 0.71$ & $4.86 \pm 0.05$ \\
P5 & $480.5 \pm 4.73$ & $9.11 \pm 0.72$ & $4.89 \pm 0.04$ \\
P6 & $481.2 \pm 4.39$ & $8.66 \pm 0.63$ & $4.85 \pm 0.05$ \\
P7 & $481.0 \pm 5.25$ & $9.18 \pm 0.72$ & $4.90 \pm 0.04$ \\
P8 & $480.8 \pm 4.48$ & $8.43 \pm 0.81$ & $4.87 \pm 0.05$ \\
P9 & $481.1 \pm 5.13$ & $8.83 \pm 0.66$ & $4.90 \pm 0.03$ \\
P10 & $980.9 \pm 4.09$ & $9.22 \pm 0.41$ & $4.88 \pm 0.04$ \\
P11 & $480.5 \pm 4.13$ & $8.73 \pm 0.56$ & $4.88 \pm 0.03$ \\
\hline
\end{tabular}

SD: Standard deviation

Table 8: Lag time and $\mathrm{t}_{90 \%}$ of all batch press-coated tablets

\begin{tabular}{|c|c|c|c|c|c|c|c|c|c|c|c|}
\hline Formulation & P1 & P2 & P3 & P4 & P5 & P6 & P7 & P8 & P9 & P10 & P11 \\
\hline Lag time (h) & 2.17 & 2.58 & 3.67 & 4.13 & 4.75 & 5.18 & 6.08 & 1.41 & 2.83 & 4.66 & 5.92 \\
\hline$t_{90 \%}(h)$ & 3.5 & 4.5 & 6.0 & 6.5 & 7.5 & 8.0 & 9.0 & 2.0 & 3.5 & 5.5 & 7.0 \\
\hline
\end{tabular}


Evaluation of blends and tablets of immediate release cores The blends of all the formulations of the core tablet were found to have good flow property. The prepared core tablets were found to exhibit satisfactory tablet characteristics. The drug content of all the formulations was found to be within the IP limits. The in vitro disintegration time was found to be very less for F10 formulation, i.e. $0.31 \mathrm{~min}$. This batch tablets have shown a better dissolution profile when compared to remaining formulations. To avoid the delay in the release of the drug after the lag time, we have prepared immediate release cores; these will help in burst release of the drug due to hydrodynamic pressure created by the superdisintegrants.

Table 9: The $\mathrm{R}^{2}$ values of the optimized press-coated tablets (P11) as per different in vitro release kinetics model

\begin{tabular}{ll}
\hline Kinetics model & $\mathbf{R}^{2}$ value \\
\hline Zero order & 0.519 \\
First order & 0.436 \\
Hixson-Crowell & 0.475 \\
Higuchi & 0.349 \\
Korsmeyer-Peppas & 0.441 \\
\hline
\end{tabular}

Drug release kinetics of optimized core tablets

From the $\mathrm{R}^{2}$ values of the optimized formulation C10 as per different in vitro release kinetics model, it was found that the immediate release core tablets have followed the first-order kinetics, i.e., the drug release rate is concentration dependent.

\section{Evaluation of press-coated tablets}

The prepared press-coated tablets were found to exhibit satisfactory tablet characteristics. As coating level increases, mechanical strength of coat also increases and the media permeation rate at a higher thickness reduces. Fast disintegrating tablet core with $360 \mathrm{mg}$ barrier layer of EC20 and L-HPC LH11 in ratio 14:1 provided lag time of nearly $6 \mathrm{~h}$. The coating material started rupturing at $5.9 \pm 0.02 \mathrm{~h}$ and showed burst drug release after $\mathrm{t}_{90 \%}=7 \mathrm{~h}$.

Drug release kinetics of the optimized press-coated tablets From the $\mathrm{R}^{2}$ values of the optimized press-coated tablet P11 as per different in vitro release kinetics models, it was found that the burstrelease pulsatile tablets have followed the zero-order kinetics, i.e., the drug release rate is concentration independent.

Table 10: Stability study of formulation $\mathrm{P} 11$ at $40^{\circ} \mathrm{C} \pm 2^{\circ} \mathrm{C}, 75 \pm 5 \% \mathrm{RH}$

\begin{tabular}{|c|c|c|c|c|c|}
\hline \multirow[t]{2}{*}{ Time (months) } & \multirow{2}{*}{$\begin{array}{l}\text { Thickness } \\
(\mathrm{mm}) \pm S D(n=3)\end{array}$} & \multirow{2}{*}{$\begin{array}{l}\text { Hardness }(\mathrm{kg} / \\
\left.\mathrm{cm}^{2}\right) \pm S D(\mathrm{n}=3)\end{array}$} & \multirow{2}{*}{$\begin{array}{l}\text { Drug } \\
\text { content }(\%) \pm \operatorname{SD}(n=3)\end{array}$} & \multicolumn{2}{|c|}{ In vitro drug release $\pm \operatorname{SD}(n=6)$} \\
\hline & & & & Lag time (h) & t90\%(h) \\
\hline 0 & $4.88+0.03$ & $17.13+0.56$ & $99.75+0.22$ & $5.9+0.02$ & 7 \\
\hline 1 & $4.87+0.04$ & $17.43+0.72$ & $99.56+0.22$ & $5.9+0.03$ & 7 \\
\hline 3 & $4.87+0.03$ & $18.19+0.46$ & $99.29+0.22$ & $5.8+0.03$ & 7 \\
\hline 6 & $4.89+0.03$ & $18.83+0.68$ & $99.17+0.22$ & $5.8+0.02$ & 7 \\
\hline
\end{tabular}

SD: Standard deviation
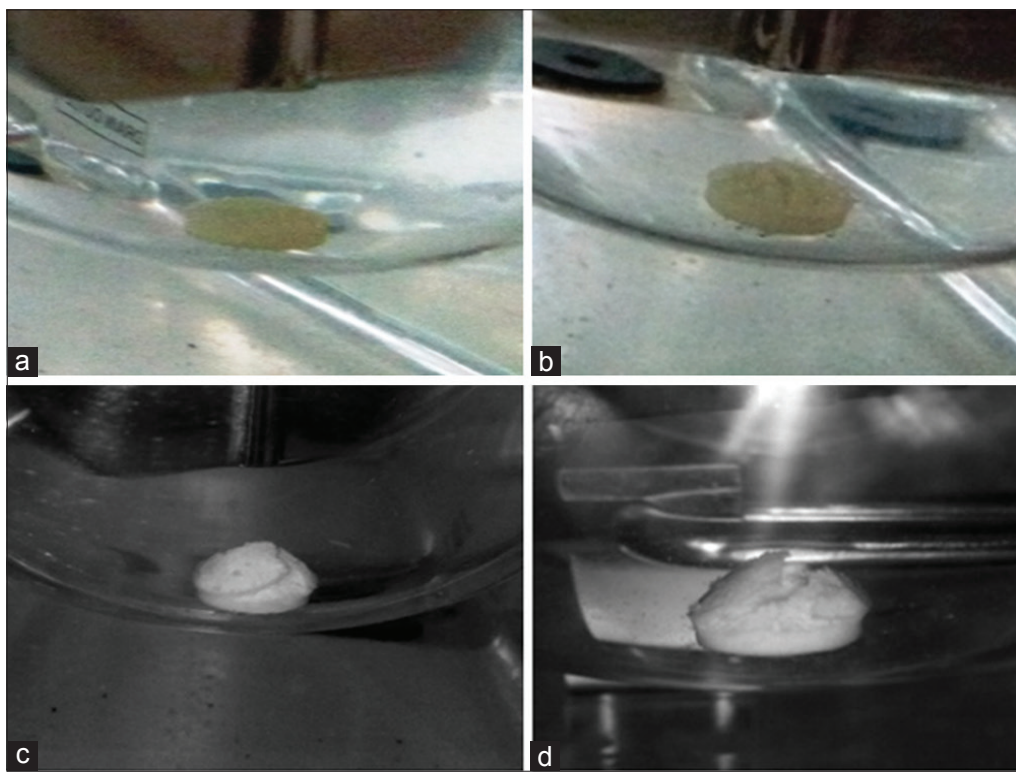

Fig. 13: The release pattern of the optimized press-coated tablets (P11) in (a) $5 \mathrm{~h}$, (b) $5.5 \mathrm{~h}$, (c) $6 \mathrm{~h}$, (d) $6.5 \mathrm{~h}$

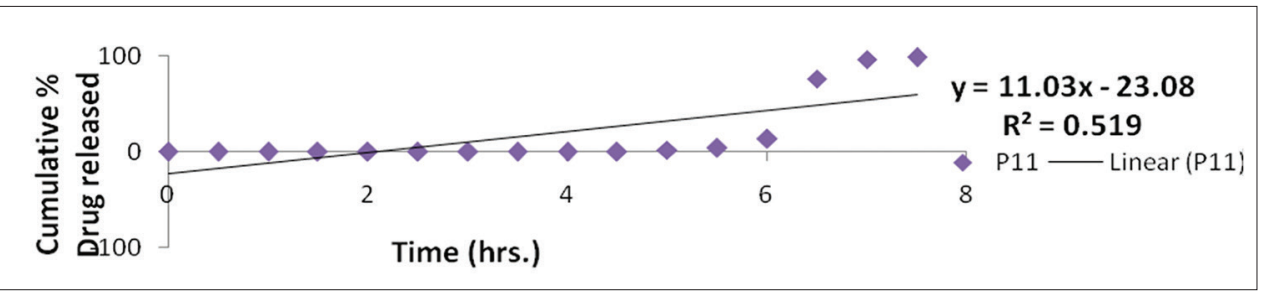

Fig. 14: In vitro release zero-order plot for optimized press-coated tablets P11 


\section{Stability studies}

6 months' stability studies revealed the physical and chemical stability of the formulations as there were no significant changes in color, thickness, hardness, drug content, and dissolution profile.

\section{CONCLUSION}

Over the past decades, there has been a growing appreciation on the importance of circadian rhythms on GI tract physiology and to disease states. In the present study, an effort is made to formulate and evaluate time-controlled single unit pulsatile tablets of salbutamol sulfate. The immediate drug releasing core tablets were formulated and presscoated for intentionally delaying the drug release from therapeutic point of view in the treatment of nocturnal asthma, where peak symptoms are observed in the early morning.

The results from FTIR spectroscopy revealed that the drug and polymers used were satisfactorily compatible. Time-controlled pulsatile release tablets of salbutamol sulfate with a lag time of nearly $6 \mathrm{~h}$ were successfully prepared to treat the nocturnal asthma symptoms. Fast disintegrating core tablets were prepared by direct compression method and press-coated. Lag time is dependent on the coating level and nature of coating polymer. Coating with HPMC forms swelling barrier layer, whereas coating with EC and L-HPC forms rupture polymer layer. The drug release was rapid and complete from the barrier layer-containing $\mathrm{L}-\mathrm{HPC}+\mathrm{EC}$ as compared to EC+HPMC. The drug release rate of the immediate release core tablets is concentration dependent whereas that of brust-release pulsatile tablets is concentration independent.

\section{REFERENCES}

1. Hussain SK, Firoz S, Ramya EM, Sarada K, Ramesh B, Jagadesh K. A review of chronopharmaceutical drug delivery system. Int J Med Pharm Res 2015;3:942-7.

2. Kumar JP, Muzib YI, Misra G. Preparation and evaluation of pulsatile drug delivery of fluvastatin sodium. Asian J Pharm Clin Res 2016;9:348-51.

3. Rewar S, Bansal BK, Singh CJ, Sharma AK. Pulsatile drug delivery release technologies: An overview. Int J Res Dev Pharm Life Sci 2015;4:1386-93.

4. Bhuvaneswari S, Manivannan S, Akshay M, Nify F. Formulation and evaluation of gastroretentive microballoons of Acebrophylline for the treatment of bronchial asthma. Asian J Pharm Clin Res 2016;9:105-11.

5. Chandra JR, Arora K, Anuragi N, Kaushal R, Jain V. Pulsatile drug delivery system: A promising delivery system for controlled drug release. Eur J Pharm Med Res 2015;2:564-75.

6. Richard JM. Nocturnal asthma: Circardian rhythms and therapeutic interventions. Am Rev Respir Dis Suppl Airway Dis Update 1993;147:S25-8

7. Global Strategy for Asthma Management and Prevention. GINA Appendix 2015 Update. Mechanisms of Asthma; 2015. p. 21.

8. Richard JM, Schlegel SB. Chronobiology of asthma. Am J Respir Crit Care Med 1998;158:1002-7.

9. Tripathi KD. Essentials of Medical Pharmacology. $6^{\text {th }}$ ed. New Delhi, India: Jaypee Brothers Medical Publishers; 2010. p. 216-27.

10. Goldstein DA, Tan YK, Soldin SJ. Pharmacokinetics and absolute bioavailability of Salbutamol in healthy adult volunteers. Eur J Clin Pharmacol 1987;32:631-4.

11. Drug Bank. Available from: http://www.drugbank.ca/drugs/DB01001. [Last accessed on 2016 Jan 29].

12. Kumar A, Maurya R. Formulation and evaluation of press-coated pulsatile tablets of salbutamol sulphate. J Sci Innov Res 2012;1:74-87.

13. Patel T, Ananthapur M, Sabitha JS, Tribedi S, Mathappan R, Prasanth VV. Formulation and evaluation of erodible pulsatile drug delivery system of Salbutamol sulphate for nocturnal asthma. Int J Pharm Innov 2013;3:24-35.

14. Malladi M, Jukanti R. Floating pulsatile drug delivery system of famotidine: Design, statistical optimization, and in vitro evaluation. Int J Pharm Sci 2016;8:169-81.

15. Wadhwa R, Sharma Y, Upadhyay RP, Bala K. Pulsatile release of ketoprofen from compression coated tablets using eudragit ${ }^{\circledR}$ polymers. Int J Pharm Pharm Sci 2016;8:224-9. 